\title{
Historiador e/ou professor de História: a formação nos cursos de graduação de História
}

Historian and/or history teacher: training on History graduation

Claudia Sapag Ricci*

\section{RESUmo}

$\mathrm{O}$ artigo aborda o processo de normatização curricular dos cursos de História quando, na década de 1990, o Ministério da Educação delineou parâmetros de elaboração das estruturas curriculares e perfil profissional do historiador a ser perseguido nacionalmente e, em 2001, o Conselho Nacional de Educação aprovou as Diretrizes Curriculares dos Cursos de História. Focaliza a relação dessas diretrizes com os projetos pedagógicos, o perfil profissional do historiador, a polêmica instaurada em relação à distinção entre bacharelado e licenciatura nos cursos de História e a inclusão de políticas de patrimônio histórico, preservação do meio ambiente, direitos à pluralidade e à cidadania cultural, como fundamentais para a atuação do historiador.

Palavras-chave: Diretrizes Curriculares; cursos de História; historiador.

\section{Abstract}

The article discusses the curricular standardization process of history courses when in the nineties of the twentieth century the Ministry of Education outlined development parameters of curriculum and professional historian profile structures being pursued nationally and in 2001, the National Council Education approved the Curriculum Guidelines for history courses. It focuses on the relationship of these guidelines with educational projects, the professional historian profile, the controversy brought regarding the distinction between a degree in History and courses and the inclusion of heritage policies, preservation of the environment, rights for plurality and cultural citizenship as fundamental to the work of the historian.

Keywords: Curriculum Guidelines; History courses; historian.

\footnotetext{
* Professora Associada da Universidade Federal de Minas Gerais (UFMG). Pesquisadora (LABEPEH - CP/FAE/UFMG). ricci.clau@gmail.com
} 


\section{Autonomia VERSUS Normatização}

Os cursos de graduação precisam se conduzidos, através das Diretrizes Curriculares, a abandonar as características de que muitas vezes se revestem, quais sejam as de atuarem como meros instrumentos de transmissão de conhecimento e informações, passando a orientar-se para oferecer uma sólida formação básica, preparando o futuro graduado para enfrentar os desafios das rápidas transformações da sociedade, do mercado de trabalho e das condições de exercício profissional. (Parecer $\mathrm{n}^{\circ} 776 / 97-\mathrm{CNE}$ )

No contexto atual, quando são publicados, no Diário Oficial da União, ${ }^{1}$ a homologação do Parecer e a Resolução do Conselho Nacional de Educação sobre as Diretrizes Curriculares Nacionais para a Formação Inicial e Continuada dos Profissionais do Magistério da Educação Básica, o trecho citado, do Parecer n 776/97 - Orientação para as diretrizes curriculares dos cursos de graduação, do Conselho Nacional de Educação (CNE), é revelador de uma trajetória de quase duas décadas em que a formação docente, nos cursos de graduação, tem ocupado fóruns de entidades científicas, debates entre especialistas, páginas da mídia - impressa ou virtual -, e polêmico processo de normatização. O referido trecho expressa a expectativa de seus autores em relação às mudanças necessárias, a serem implementadas pelas instituições de ensino superior em seus chamados cursos de formação inicial, considerando as demandas e "desafios" postos pelas "rápidas transformações da sociedade, do mercado de trabalho e das condições de exercício profissional”. Esse documento faz referência à necessidade de revisão curricular dessas instituições que, até a determinação da LDB no 9394/06, pautavam-se por uma estrutura curricular caracterizada por excessiva rigidez advinda, em grande parte, pela fixação detalhada de conteúdos mínimos curriculares e resultando na progressiva diminuição da margem de liberdade que foi concedida às instituições para organizarem suas atividades de ensino. Ainda segundo o documento, as diretrizes curriculares seriam orientações para a elaboração dos novos currículos e deveriam pautar-se pelos seguintes princípios:

1. Assegurar às instituições de ensino superior ampla liberdade na composição da carga horária a ser cumprida para a integralização dos currículos, assim como na especificação das unidades de estudos a serem ministradas; 
2. Indicar os tópicos ou campos de estudo e demais experiências de ensino-aprendizagem que comporão os currículos, evitando ao máximo a fixação de conteúdos específicos com cargas horárias predeterminadas, as quais não poderão exceder $50 \%$ da carga horária total dos cursos;

3. Evitar o prolongamento desnecessário dos cursos de graduação;

4. Incentivar uma sólida formação geral, necessária para que o futuro graduado possa vir a superar os desafios de renovadas condições de exercício profissional e de produção do conhecimento, permitindo variados tipos de formação e habilitações diferenciadas em um mesmo programa;

5. Estimular práticas de estudo independente, visando uma progressiva autonomia profissional e intelectual do aluno;

6. Encorajar o reconhecimento de saberes, habilidades e competências adquiridos fora do ambiente escolar, inclusive os que se refiram à experiência profissional julgada relevante para a área de formação considerada;

7. Fortalecer a articulação da teoria com a prática, valorizando a pesquisa individual e coletiva, assim como os estágios e a participação em atividades de extensão;

8. Incluir orientações para a condução de avaliações periódicas que utilizem instrumentos variados e sirvam para informar docentes e discentes acerca do desenvolvimento das atividades didáticas.

Dentre os princípios, ressalta-se o encaminhamento para uma maior flexibilização e liberdade das instituições no estabelecimento de seus currículos. No entanto, outro documento, o Parecer no 583/2001, do Conselho Nacional de Educação e da Câmara de Educação Superior, buscou explicitar os limites dessa autonomia na formulação curricular: "é fundamental não confundir as diretrizes que são orientações mandatórias, mesmo às universidades ... com parâmetros ou padrões - standards - curriculares que são referenciais curriculares detalhados e não obrigatórios". O voto do relator apresenta, nesse parecer, uma estrutura ou roteiro para a formulação das diretrizes curriculares:

a. Perfil do formando/egresso/profissional - conforme o curso, o projeto pedagógico deverá orientar o currículo para um perfil profissional desejado.

b. Competência/habilidades/atitudes.

c. Habilitações e ênfases. 
d. Conteúdos curriculares.

e. Organização do curso.

f. Estágios e Atividades Complementares.

g. Acompanhamento e Avaliação.

Esse parece ter sido o modelo seguido pelas Comissões de Especialistas das diferentes áreas de conhecimento para a elaboração das diretrizes curriculares dos seus respectivos cursos de graduação, ao longo da primeira década do século XXI.

\section{LiCENCIATURA E BACHARELADO - ENSINO E PESQUISA}

No caso específico dos cursos de História as diretrizes curriculares ${ }^{2}$ foram objeto de discussão e debate no interior das instituições, sendo, muitas vezes, utilizadas para uma revisão curricular ou, até mesmo, transformadas, por muitos cursos e programas, como projetos pedagógicos.

No entanto, é possível identificar o movimento institucional do Ministério da Educação para delinear estruturas curriculares dos cursos universitários de História, assim como o perfil profissional do historiador desde a década de 1980, alimentado pelo intenso debate no meio educacional e entre os profissionais de História.

Em 1986, foi publicado o documento intitulado Diagnóstico e Avaliação dos Cursos de História no Brasil, resultado do trabalho de um grupo de consultores (professores de diferentes regiões do Brasil e a presidência da Associação Nacional dos Professores Universitários de História - Anpuh), convocados pela Secretaria da Educação Superior - SESu-MEC. ${ }^{3}$

Iniciando seus trabalhos em 1981, o grupo encaminhou um questionário a todos os cursos de História existentes no país. A divulgação da atividade ocorreu em uma mesa-redonda coordenada pelo grupo de consultores, no XI Simpósio Nacional da Anpuh, em João Pessoa, em julho daquele mesmo ano, com expressiva participação de professores e alunos. Na ocasião, muitos alunos reivindicaram participação no trabalho do Grupo de Consultores, e definiu-se que esta se daria por meio dos debates e reflexões internos aos departamentos. 
Um novo documento, com a sistematização dos dados levantados mediante questionários, foi enviado aos departamentos, e alguns encontros regionais foram realizados. Posteriormente, o grupo de consultores elaborou um relatório síntese com as seguintes questões: dados gerais sobre o corpo docente; período de funcionamento do curso de graduação em História; informações sobre o alunado; estrutura do departamento de História; ciclo básico; Introdução aos Estudos Históricos; Bacharelado e Licenciatura; Articulação com o Ensino de $1^{\circ}$ e $2^{\circ}$ graus; pesquisa; interação entre disciplinas.

A partir da análise dos questionários respondidos, documentos enviados pelos departamentos de História ${ }^{4}$ e debates realizados, o grupo de consultores chegou a várias conclusões: existência de instituições com um corpo bastante reduzido (cerca de 3 a 7 docentes) e outras bem maiores (40 a 56 docentes); especialmente nas instituições privadas, prevalece um número significativo de profissionais não graduados em História, e, na grande maioria, predominam graduados, ao passo que nas instituições públicas há "um número significativo de mestres, embora ainda minoria, enquanto em todas elas são muito escassos os doutores"; a predominância do regime de trabalho do "professor horista", sendo minoria o tempo integral e rara a dedicação exclusiva (apenas nas instituições públicas).

Em relação à estrutura do departamento, a pesquisa sugere uma centralização e mesmo personificação na figura do coordenador ou chefe. Segundo o documento, "a discussão, a participação coletiva nas decisões acadêmicas não constitui a norma, pelo contrário, pois predomina um certo centralismo personalista cujas características concretas só podemos presumir”.

Dentre as questões levantadas, a da organização curricular merece destaque pelo Grupo de Consultores como uma das mais importantes a serem discutidas: "o atual currículo mínimo deve ser mantido, modificado ou substituído por outro? Modificado em que termos? Quais os princípios norteadores de um outro currículo? (note-se que se trata de 'currículo mínimo' e não de 'currículo pleno')" ${ }^{5}$

Apenas metade das instituições revela a existência de um ciclo básico, conforme indicava a legislação da época. As ideias mais comuns que justificavam a existência de um ciclo básico eram: "a preparação para o curso de História, suprir as insuficiências do $2^{\circ}$ grau, sentido propedêutico". Raramente, indicavam o ciclo básico como possibilidade de espaço comum para vários 
cursos, ou mesmo para a licenciatura e bacharelado. A grande maioria indica a necessidade de substituir o atual ciclo básico por outro, constituído por disciplinas do próprio curso de história, em nível introdutório. O grupo de consultores constata que não existe interação entre disciplinas oferecidas pelos cursos de história.

A maioria das instituições só possui licenciatura, ou seja, oferece disciplinas pedagógicas em seu currículo. O bacharelado, ao contrário, se caracteriza pela ausência de disciplinas pedagógicas e pela ênfase na pesquisa (embora se trate muito mais de disciplinas sobre a pesquisa do que da pesquisa propriamente dita. Talvez isso possa explicar o fato de ser muito rara a exigência de uma monografia final de Bacharelado).

Surpreendentes, atualmente como na época do diagnóstico, são os dados sobre a questão da relação com as Faculdades de Educação ou os Departamentos de Pedagogia:

não transparecem críticas ou restrições, como talvez fosse possível imaginar. Pelo contrário, o que as informações revelam é a existência, sobretudo nas instituições maiores, de todo um conjunto de práticas que visam aproximar os departamentos interessados, bem como uma preocupação muito grande com sondagens, contatos, cursos voltados para a realidade do ensino de $1^{\circ} \mathrm{e} 2^{\circ}$ graus.

Para o grupo de consultores, parece existir uma tendência a rejeitar a dicotomia licenciatura versus bacharelado, e necessidade de maior entrosamento entre os departamentos de história e os departamentos e faculdades de educação. Mais de 20 anos após a realização desse levantamento, a questão "licenciatura e bacharelado" parece persistir como ponto central na pauta dos debates e posicionamentos dos cursos de História em nosso país, conforme revela a pesquisa realizada em 2001 pelo Ministério de Educação. ${ }^{6}$

A maioria das instituições menores indica o fato de seus professores e mesmo alunos já atuarem no ensino fundamental e médio (na época denominado ensino de $1^{\circ}$ e $2^{\circ}$ graus) como fator da articulação desse segmento com a universidade. As instituições maiores, especialmente as públicas, indicam preocupações do departamento com essa interação, mas tais preocupações não estão, necessariamente, incluídas no currículo do curso de História.

Diante desse contexto, o grupo de consultores reconhece que tal articulação não existe, apesar da consciência do problema. 
Uma situação similar é detectada em relação à articulação "Ensino e Pesquisa". Segundo o grupo de consultores, havia consenso quanto à indissociabilidade entre ensino e pesquisa, mas dificuldade de concretizar tal pressuposto. O grupo destaca que mais do que ser inaceitável a separação entre ensino e pesquisa, é compreender ou associar licenciatura a ensino e bacharelado a pesquisa. Um agravante é a constatação da inexistência de uma política de pesquisa nos departamentos de História. Segundo o levantamento, pesquisa, em alguns casos, resume-se à disciplina Métodos e Técnicas, e até mesmo é indicada apenas como sinônimo de trabalhos escolares, estágios ou monografia. ${ }^{7}$

No momento da realização do diagnóstico pelo grupo de consultores, início da década de 1980, uma questão amplamente debatida pela categoria de profissionais de história era a existência dos cursos de Estudos Sociais, símbolo da tentativa dos governos militares em descaracterizar o ensino de História e Geografia e disseminar o ideário moral e cívico. Dessa forma, em relação a essa questão, o grupo de consultores atesta uma unanimidade de opiniões e indicações dos departamentos de História:

$1^{\circ}$ ) Questionamento da Lei 5692/71, tanto em seus pressupostos quanto nos efeitos;

$2^{\circ}$ ) Condenação veemente aos chamados "Estudos Sociais", quer como "disciplina" ou "área de estudos" (sic), quer como objeto de cursos específicos de "licenciatura curta";

$3^{\circ}$ ) Explicitação dos efeitos nocivos advindos para o ensino e para o professorado em consequência da instituição dos "Estudos Sociais";

$4^{\circ}$ ) Supressão dos atuais cursos de "Estudos Sociais", começando pela proibição de realizarem novos vestibulares, e solução adequada para os seus atuais alunos. Em todos os documentos, em maior ou menor grau, o que se sugere é a extinção pura e simples dos "Estudos Sociais" no $1^{\circ}$ e no $2^{\circ}$ graus, fazendo-se acompanhar tal providência, urgente, de uma intensa mobilização com o objetivo de reorganizar e revitalizar o ensino da História naqueles dois níveis. ${ }^{8}$

Se, por um lado, a questão dos Estudos Sociais não está mais tão presente hoje, por outro, é preciso destacar o seu caráter político e a maneira como marcou a discussão curricular. Revela a íntima relação entre as questões 
educacionais, sociais e políticas, especialmente no debate das ciências humanas. Tal era a relevância da questão "Estudos Sociais" naquele momento que o documento alvo de análise (Diagnóstico e Avaliação dos Cursos de História: documento final - 1986) traz, além dos dados apresentados pelos questionários, documentos e debates com os departamentos de História, um texto intitulado “A questão de Estudos Sociais”, elaborado com a colaboração de uma professora do Grupo de Consultores da área de Geografia. ${ }^{9}$

O grupo de consultores elegeu alguns temas para a indicação de suas conclusões, ${ }^{10}$ com base nos quais fez uma proposta de implementação de um Programa Integrado de Melhoria do Ensino de Graduação em História (Pimeg), mediante atividades agrupadas em: 1. Apoio Docente; 2. Apoio Bibliográfico e de Biblioteca; 3. Projeto Editorial; e 4. Melhoria de Instalações e Equipamentos. Sugere que a SESu/MEC faça a coordenação do Pimeg com a assessoria de especialistas de universidades de diferentes estados brasileiros.

Em síntese, a análise global dos cursos de História, após o período de democratização do país - década de 1980 -, apresenta as seguintes questões: a) existência de forte centralismo na coordenação dos departamentos e ausência de instâncias coletivas como colegiado; b) predominância de um regime de trabalho (horista) que dificultava a articulação entre disciplinas e papel político mais relevante do corpo docente (sua constituição); c) bacharelado com ênfase em técnicas de pesquisa (sem definição de linhas de pesquisa, apenas disciplinas como Métodos e Técnicas ou similares); d) licenciatura com uma concepção pragmática (valorização das técnicas didáticas) e desarticulada do bacharelado.

\section{INSTRUMENTAL PARA ANÁLISE OU AQUISIÇÃO DE INFORMAÇÕES?}

A década de 1990 foi palco de inúmeras iniciativas governamentais no campo educacional: Lei de Diretrizes e Bases da Educação Nacional no 9394/96; elaboração dos Parâmetros Curriculares Nacionais; definição de diretrizes curriculares para os cursos de graduação; programa de análise dos livros didáticos e implementação do Plano Nacional do Livro Didático (PNLD), e implantação do Sistema de Avaliação da Educação Básica (SAEB). 
Em relação aos cursos de graduação, a SESu/MEC convoca Comissões de Especialistas de Ensino para a elaboração de critérios para a avaliação de cursos de graduação e consequente autorização para funcionamento.

Em fevereiro de 1997, a Comissão de Especialistas do Ensino de História ${ }^{11}$ estabelece os critérios para análise de projetos de cursos de História. Tais critérios são utilizados atualmente segundo formulários existente no site da SESu/ MEC, com algumas alterações: exclusão do primeiro item, "Necessidade Social", e alteração na pontuação para atribuição dos conceitos. A existência desse item como um dos critérios para avaliação estava baseada no inciso I, do artigo $3^{\circ}$ da Portaria 181/96, que determina:

Da necessidade social: a) caracterização da área ou região de influência do curso pretendido em seus aspectos sociais, econômicos e culturais; b) justificativa da necessidade social do curso, utilizando, dentre outras considerações, indicadores relativos a: 1 - conclusões do ensino médio nos três anos letivos anteriores e projeção para os três anos seguintes; 2 - grau de interesse pelo curso ou área, demonstrado pela relação candidato/vaga nos concursos vestibulares, pelo número de cursos, matrículas e formandos no curso na região, nos três anos anteriores ao pedido; 3 - importância do curso para o desenvolvimento socioeconômico da região, utilizando as informações disponíveis sobre o mercado de trabalho.

A indicação feita pela Comissão de Especialistas do Ensino de História, em 1997, era a de que no item Necessidade Social fossem analisados e avaliados os dados e informações prestados pela IES, "valorizando a efetiva existência de análise de dados que evidenciem a necessidade do curso, indo além do mero arrolamento de informações sobre a região". ${ }^{12}$ De certa forma, a exclusão desse item para avaliação dos cursos de História parece indicar uma desconsideração com a realidade vivida pela região onde se pretende implantar o curso de História.

Além da exclusão do item Necessidade Social, a alteração da pontuação dos itens pode ser reveladora de uma mudança mais profunda na concepção de um curso de História. Exceto o item Estrutura Curricular, todos os outros sofreram uma nova valoração. Os itens cujo peso aumentou foram os relacionados ao Corpo docente (Titulação; Adequação às áreas de atuação; Relação docente/disciplina; Dedicação e Regime de trabalho; Políticas de qualificação, 
carreira e remuneração), e aqueles cujo peso diminuiu foram os seguintes: Biblioteca; Laboratórios e equipamentos; Infraestrutura física; Programas de apoio e acompanhamento discente e Administração acadêmica do curso.

Tais alterações podem ter sido resultado de uma mera mudança técnica mas podem, também, revelar uma valorização dos aspectos relacionados ao corpo docente da instituição e uma desvalorização da infraestrutura (incluindo biblioteca e laboratório) e de políticas mais diretamente relacionadas ao corpo discente.

Segundo o histórico apresentado no texto introdutório sobre as Diretrizes Curriculares para os Cursos de Graduação, ${ }^{13}$ o edital no 4/97 faz uma convocação a todas as Instituições de Ensino Superior para que apresentem propostas para as diretrizes curriculares dos cursos de graduação. ${ }^{14}$ Ainda segundo o documento citado, foram encaminhadas cerca de 1.200 propostas de universidades, faculdades, organizações profissionais, organizações docentes e discentes, tanto do setor público como do privado. Simultaneamente a essa convocação, diversas instituições de ensino superior organizaram debates, seminários e encontros com a presença de representantes da Secretaria de Ensino Superior (SESu/MEC) e do Fórum Nacional de Pró-Reitores de Graduação (ForGrad). ${ }^{15}$ As Comissões de Especialistas de Ensino foram convocadas para sistematizarem as sugestões apresentadas e produzirem as propostas a serem encaminhadas ao Conselho Nacional de Educação. Tais propostas foram disponibilizadas na Internet para avaliação e análise de interessados, especialistas e instituições de ensino. Em 27 de novembro de 1998, o Fórum Nacional de Coordenadores de Pós-Graduação em História sugere alterações no texto das Diretrizes Curriculares dos Cursos de História. Novamente as propostas sistematizadas foram divulgadas pela Internet com o objetivo de suscitar sugestões e críticas ao documento inicial. Além do debate eletrônico, encontros e seminários são organizados e têm como pauta a discussão das propostas de diretrizes curriculares dos cursos de graduação.

A SESu encaminhou o documento das diretrizes gerais em separado da discussão dos conteúdos de cada curso para o Conselho Nacional de Educação. As propostas foram agrupadas segundo os critérios da Capes. Dessa forma, História ficou no bloco CIÊNCIAS HUMANAS E SOCIAIS, junto a Artes Cênicas, Artes Visuais, Ciências Sociais, Direito, Filosofia, Geografia, Letras, Música, Pedagogia e Psicologia. 
As propostas de diretrizes curriculares para os cursos de licenciatura foram encaminhadas posteriormente. Constituiu-se um grupo de especialistas na questão da formação de professores para formular orientações e características das licenciaturas como formação profissional.

As alterações realizadas nos textos revelam o caminho do questionamento realizado. O que pode, por um lado, parecer mero detalhe de redação, por outro lado revela um pouco do processo conflituoso da elaboração das diretrizes curriculares dos cursos de graduação de História.

Um contraponto entre o documento Diretrizes Curriculares de História, datado de $1998,{ }^{16}$ e o aprovado pelo Parecer CNE/CES no 492/2001 permite a percepção desse processo.

A parte introdutória dos documentos - intitulada "Preâmbulo" (no primeiro documento) e "Introdução" (no segundo documento) - apresenta-se praticamente idêntica, a não ser pela atualização da denominação "ensino fundamental e médio" no lugar de "primeiro e segundo graus" e pelo corte da última frase:

Diretrizes estas cuja proposta, elaborada em conjunto pela Anpuh (Associação Nacional de História) e pela Comissão de Especialistas de Ensino em História nomeada pelo MEC-SESu, em trabalho consciencioso e detalhado que se desenvolveu de fins de junho a meados de novembro de 1998 e que incluiu a cuidadosa consolidação das opiniões emitidas por numerosas instituições de ensino superior, passamos a expor.

O que pode significar a ausência dessa frase no documento final, aprovado pelo parecer CNE/CES n 492/2001? Uma frase que contextualiza a produção do documento, tanto em termos temporais (fins de junho a meados de novembro de 1998) como do processo de envolvimento da comunidade acadêmica (Anpuh e numerosas instituições de ensino superior), é bem-vinda, especialmente num texto de historiadores, assim como lhe atribui um respaldo ainda maior.

Outro exemplo de alteração é o tópico que define o perfil do graduado em História, que sofre alterações até mesmo em seu título - de "Perfil Profissional", passa para "Perfil dos Formandos". No texto de 1988, aparece o seguinte:

O graduado deverá estar capacitado ao exercício do trabalho de Historiador, em todas as suas dimensões, o que supõe pleno domínio da natureza do conhecimen- 
to histórico e das práticas essenciais de sua produção e difusão. Atendidas estas exigências básicas e conforme as possibilidades, necessidades e interesses das IES, com formação complementar e interdisciplinar, o profissional estará em condições de suprir demandas sociais relativas ao seu campo de conhecimento (magistério em todos os graus, preservação do patrimônio, assessorias a entidades públicas e privadas nos setores culturais, artísticos, turísticos etc.), uma vez que a formação do profissional de História se fundamenta no exercício da pesquisa.

Uma alteração aparece no mesmo documento, datado de 1999:

O graduado deverá estar capacitado ao exercício do trabalho de Historiador, em todas as suas dimensões, o que supõe pleno domínio da natureza do conhecimento histórico e das práticas essenciais de sua produção e difusão. Atendidas estas exigências básicas e conforme as possibilidades, necessidades e interesses das IES, com formação complementar e interdisciplinar, o profissional estará em condições de suprir demandas sociais relativas ao seu campo de conhecimento (magistério em todos os graus, preservação do patrimônio, assessorias a entidades públicas e privadas nos setores culturais, artísticos, turísticos etc.). Neste sentido, não se deve pensar em um curso que forme apenas professores, uma vez que a formação do profissional de História se fundamenta no exercício da pesquisa, não podendo a formação docente ser compreendida sem o desenvolvimento de sua capacidade de produzir conhecimentos. ${ }^{17}$

No entanto, as Diretrizes Curriculares dos Cursos de História, aprovadas pelo Parecer CNE/CES no 492/2001, se aproximam mais da formulação anterior, excluindo a última frase:

O graduado deverá estar capacitado ao exercício do trabalho de Historiador, em todas as suas dimensões, o que supõe pleno domínio da natureza do conhecimento histórico e das práticas essenciais de sua produção e difusão. Atendidas estas exigências básicas e conforme as possibilidades, necessidades e interesses das IES, com formação complementar e interdisciplinar, o profissional estará em condições de suprir demandas sociais relativas ao seu campo de conhecimento (magistério em todos os graus, preservação do patrimônio, assessorias a entidades públicas e privadas nos setores culturais, artísticos, turísticos etc.).

A frase reformulada ou retirada tratava da importância da pesquisa na formação do profissional de História, independentemente do local ou 
instituição de sua atuação (ensino ou preservação do patrimônio). No entanto, a formulação parecia reforçar a tão polêmica dicotomia entre licenciatura e bacharelado e a postura de setores da universidade que parecem desconsiderar o fato de que a esmagadora maioria dos formandos em História das diferentes universidades brasileiras, públicas ou privadas, tem o ensino como seu campo de trabalho.

Tal questão parece ter sido também a razão de outras alterações nos textos das diretrizes curriculares dos cursos de graduação de História. No tópico Competências e Habilidades, houve uma reestruturação que revela a distinção entre a formação para o bacharelado e para a licenciatura. No documento de 1998, são listados cinco itens:

1. Dominar as diferentes concepções metodológicas que referenciam a construção de categorias para a investigação e a análise das relações sócio-históricas;

2. Problematizar, nas múltiplas dimensões das experiências dos sujeitos históricos, a constituição de diferentes relações de tempo e espaço;

3. Conhecer as interpretações propostas pelas principais escolas historiográficas, de modo a distinguir diferentes narrativas, metodologias e teorias;

4. Transitar pelas fronteiras entre a História e outras áreas do conhecimento, sendo capaz de demarcar seus campos específicos e, sobretudo, de qualificar o que é próprio do conhecimento histórico;

5. Desenvolver a pesquisa, a produção do conhecimento e sua difusão não só no âmbito acadêmico, mas também em instituições de ensino, em órgãos de preservação de documentos e no desenvolvimento de políticas e projetos de gestão do patrimônio cultural.

São diversas as alterações apresentadas neste item do documento aprovado pelo Parecer CNE/CES no 492/2001. Uma delas é a segmentação do tópico Competências e Habilidades em dois: A) Gerais e B) Específicas para licenciatura. Essa nova formulação, separando bacharelado e licenciatura, parece caminhar em sentido contrário aos anseios apresentados pela maioria dos cursos de graduação de História, conforme atesta o documento Projetos Pedagógicos dos Cursos de História: uma análise ${ }^{18}$ texto elaborado com base em levantamento de dados curriculares de 199 instituições de ensino superior, solicitado pela Direção de Estatísticas e Avaliação da Educação Superior (Daes/Inep), tendo como objetivo realizar o Exame Nacional do Curso de História (conhecido como Provão): 
é preciso reconhecer que, do ponto de vista pedagógico, o que mais chama atenção nessa possibilidade de chegar a um perfil consensual do historiador, é a perspectiva de uma outra possibilidade, ou seja, a superação pelas instituições de educação superior brasileiras, da dicotomia bacharelado e licenciatura, no curso de História. Essa superação representaria, em termos acadêmicos, a conquista de uma formação integral - ensino e pesquisa, articulada a um vasto e comum campo de atuação com vistas a aprofundamentos teórico-metodológicos específicos e execução prática seja, para bacharelandos seja, para licenciados.

No entanto, as Diretrizes Curriculares para os Cursos de Graduação de História, em sua versão final, aprovadas pelo Parecer CNE/CES n 492/2001, apresentam as seguintes competências e habilidades como "Específicas para licenciatura":

a) Domínio dos conteúdos básicos que são objeto de ensino-aprendizagem no ensino fundamental e médio;

b) Domínio dos métodos e técnicas pedagógicos que permitem a transmissão do conhecimento para os diferentes níveis de ensino.

Além disso, os itens indicados no documento de 1998 são apresentados no item A) "Gerais" com as seguintes mudanças:

- a substituição do conteúdo do item 3 (Conhecer as interpretações propostas pelas principais escolas historiográficas, de modo a distinguir diferentes narrativas, metodologias e teorias) pela formulação: c. Conhecer as informações básicas referentes às diferentes épocas históricas nas várias tradições civilizatórias assim como sua inter-relação;

- o acréscimo do item f.: competência na utilização da informática.

Há uma profunda diferença entre as duas formulações relacionadas ao item 3. Na primeira, existe a perspectiva de formação que instrumentaliza o historiador para inúmeras análises, ao passo que na segunda, a ênfase está na aquisição de informações.

É preciso, também, ressaltar o acréscimo do item "competência na utilização da informática" como uma das habilidades e competências do graduado em História. Ora, a necessidade do domínio dessa linguagem se faz presente, assim como de outras tantas necessárias ao trabalho com diversas fontes e linguagens, tais como cinema e televisão, por exemplo. Se a perspectiva não é 
a do tratamento de informações, mas tendo a informática como instrumento no trabalho profissional, a necessidade se faz da mesma forma que o domínio da escrita ou de outras linguagens.

É interessante notar que, na análise da programação dos cursos oferecidos pelo Centro de Referência do Professor, da Secretaria Estadual de Educação de Minas Gerais, na virada do século, há exatamente esse movimento de intensificação de ofertas de cursos instrumentais de informática e um arrefecimento de cursos e oficinas diretamente relacionados a temáticas históricas ou historiográficas. É possível arriscar uma impressão causada de "perda de identidade", na medida em que tais cursos instrumentalizam qualquer profissional (não apenas necessariamente o historiador) para o mercado, e não caminham no sentido da reflexão e prática do historiador.

O item Estruturação dos Cursos apresenta uma reformulação bastante significativa e distinta nos dois documentos. No de 1998, a formulação é a seguinte:

É condição fundamental para o desenvolvimento desta proposta a articulação entre ensino, pesquisa e extensão, a qual deverá ser garantida pelas instituições com infraestrutura material e de pessoal, através da constituição de espaços institucionais (laboratórios, núcleos etc.), que envolvam alunos de graduação, pós-graduandos, profissionais da área, e promovam um processo de reflexão crítica, trocas de experiências, permitindo a interlocução entre a universidade e a sociedade. Preservando-se o princípio geral da articulação teoria-prática, deverão ser desenvolvidas atividades no ambiente da instituição e/ou fora dela que se destinem à consolidação do perfil desejado na forma de estágios, programas de iniciação científica e/ou similares e atividades acadêmicas complementares a critério dos Colegiados/Coordenações de Cursos, às quais serão atribuídos créditos. As instituições, com autonomia, deverão estruturar seus cursos, programas, disciplinas, áreas, setores ou outras modalidades, de acordo com seus objetivos específicos, assegurada a plena formação do historiador.

O documento de 2001 apresenta a seguinte formulação para o item Estruturação dos Cursos:

Os colegiados das instituições deverão estruturar seus cursos, programas, disciplinas, áreas, setores ou outras modalidades, de acordo com seus objetivos específicos, assegurada a plena formação do historiador. Deverão incluir no seu pro- 
jeto pedagógico os critérios para o estabelecimento das disciplinas obrigatórias e optativas, das atividades acadêmicas do bacharelado e da licenciatura, e a sua forma de organização: modular, por crédito ou seriado.

O curso de licenciatura deverá ser orientado também pelas Diretrizes para a Formação Inicial de Professores da Educação Básica em cursos de nível superior.

Como se percebe, permanece apenas uma frase da primeira formulação, e ela mesma apresenta uma alteração importante: a substituição de "As instituições, com autonomia, deverão estruturar seus cursos..." por “Os colegiados das instituições deverão estruturar seus cursos". Se por um lado há a retirada da expressão "com autonomia", revelando certo "controle" da ação institucional (bastante compreensível, vindo de uma instância como o Ministério da Educação, que busca normatizar ações de instituições de todo o país), por outro, aparece a instância "colegiado", organismo que sugere um espaço coletivo de decisões. É possível resgatar a preocupação do Grupo de Consultores no diagnóstico de cursos de história no Brasil realizado há mais de duas décadas, já apresentada neste texto, sobre a necessidade de democratização na coordenação dos cursos, na medida em que havia um forte centralismo na figura do coordenador.

No item Conteúdos Curriculares, são feitas as seguintes alterações: "atividades acadêmicas" no lugar de "disciplinas"; a exclusão de "preservando as especialidades constitutivas do saber histórico e estimulando, simultaneamente, a produção e a difusão do conhecimento", final da frase do primeiro item; substituição de "permitindo o atendimento de demandas sociais dos profissionais da área” por "permitindo a diferenciação de profissionais da área"; e a inclusão da frase "No caso da licenciatura deverão ser incluídos os conteúdos definidos para a educação básica, as didáticas próprias de cada conteúdo e as pesquisas que as embasam".

No item Estágios e Atividades Complementares (inicialmente Estágios e Atividades Acadêmicas Complementares), há as seguintes alterações entre os dois documentos: no tópico número 1, troca das palavras "programas" por "cursos" e "desempenho" por "prática pedagógica": "As atividades de prática de ensino deverão ser desenvolvidas no interior dos programas / cursos de História, e sob sua responsabilidade, tendo em vista a necessidade de associar desempenho / prática pedagógica e conteúdo de forma sistemática e 
permanente"; no tópico número 2, acréscimo de detalhamento de atividades acadêmicas complementares e corte do final da última frase: "As atividades acadêmicas complementares (estágios, iniciação científica, projetos de extensão, seminários extraclasse, participação em eventos científicos) poderão ocorrer fora do ambiente escolar, em várias modalidades que deverão ser reconhecidas, supervisionadas e homologadas pelos Colegiados/Coordenações dos Cursos, totalizando, no máximo, 5\% da carga horária total (2.400 horas)"; exclusão do tópico 3: "As atividades mencionadas nos itens 1 e 2 serão acompanhadas de estágios igualmente supervisionados e homologados pelos Colegiados/ Coordenações dos Cursos".

O documento de 1998 trazia um item, excluído no documento final, denominado Formação Continuada, com a seguinte formulação:

O exercício responsável da profissão supõe um processo de formação continuada no qual as universidades desempenham papel fundamental. Neste sentido, devem ser criadas as condições institucionais com vistas à intensa articulação com a sociedade.

\section{Perfil e AtuaÇão do PROFissional de História}

A década de 1990 e os primeiros anos do século XXI foram palco para iniciativas de elaboração de diretrizes curriculares nacionais e a sua normatização, trazendo à tona uma intensa polêmica sobre as diferentes concepções a respeito de licenciatura e formação de professores. ${ }^{19}$

Em relação aos cursos de História, especificamente, a polêmica se instaurou no processo de discussão sobre a proposta de Diretrizes para o Exame Nacional de Cursos ("provão"), elaborada pela Comissão de Avaliação convocada pelo Inep. As principais críticas se referiam ao fato de tal proposta reforçar o divórcio entre bacharelado e licenciatura, e utilizar o currículo mínimo de 1962 como base para o Provão. Segundo a Anpuh,

o conteúdo estabelecido para as provas - baseado na Resolução S/N de 19 de dezembro de 1962 do CFE, que fixa conteúdos mínimos e duração do curso de História, tomando esta resolução como "o patamar comum que deve informar o Exame Nacional” - reforça princípios de definição retrógrados e ultrapassados, ignorando a experiência acumulada pela área e posicionamentos adotados pela 
Anpuh. O restabelecimento desses conteúdos desconsidera as próprias Diretrizes Nacionais aprovadas pelo Conselho Nacional de Educação para os Cursos de Graduação. Esta definição de conteúdos estimula o conservadorismo como opção de tratamento dos cursos de formação em História e não os incentiva à reformulação e inovação em seus currículos, indo na contramão dos avanços dos conhecimentos históricos e educacionais ... a comunidade dos historiadores não se sente representada nesta proposta, pois não considera possível concordar com os princípios da seleção de conteúdos para a prova e alerta para as sérias consequências que advirão do efeito multiplicador perverso que avaliações desta natureza provocarão ao ensino de História em todos os níveis. ${ }^{20}$

Apesar das críticas realizadas, é preciso destacar que o posicionamento frente às reformulações propostas não chegou a atingir um patamar de mobilização dos profissionais de História tal qual o vivenciado em relação à questão dos Estudos Sociais no início da década de 1980.

Segundo o Censo 2000, existiam no Brasil cerca de quatrocentos cursos de graduação em História, distribuídos em universidades, centros universitários, faculdades integradas, faculdades, escolas e institutos. E ainda existiam cursos de graduação em Estudos Sociais.

Para realizar o Exame Nacional do Curso de História, em 2002, o Departamento de Estatísticas e Avaliação da Educação Superior (Daes/Inep) solicitou a todos os cursos de História do país informações sobre os seus projetos pedagógicos. Mais de 50\% das instituições responderam a essa solicitação, enviando dados sobre sua organização curricular. ${ }^{21}$ Dos projetos enviados, 3 eram da região Norte, 35 da Nordeste, 21 da Centro-Oeste, 99 da Sudeste e 41 da Sul. A esmagadora maioria ( $91,4 \%$ dos projetos) oferece a modalidade Licenciatura plena em História; 20,6\% oferecem o Bacharelado em História, e 8\% dos projetos, Licenciatura plena em Estudos Sociais - habilitação História. É majoritário (53,77\%), também, o oferecimento dos cursos por instituições particulares - com exceção da região Nordeste, que apresenta $80 \%$ dos cursos em rede pública, especialmente estadual.

Segundo o documento, os Projetos Pedagógicos indicam o perfil profissional, as matrizes curriculares, a forma organizacional e funcional e a distribuição das disciplinas, com suas ementas e bibliografia. Alguns deles, demonstrando sintonia com as Diretrizes Curriculares para o Curso de História aprovadas pelo Conselho Nacional de Educação (CNE/MEC), 
apresentam também os objetivos do curso, as competências e habilidades a serem desenvolvidas. Outro grupo de instituições apresenta, em seus projetos, justificativas epistemológicas, referenciais teóricos, históricos e concepção dos cursos, programações complementares e detalhamentos didático-metodológicos ou mesmo, "reflexões sobre o tipo de missão e evolução profissional a sociedade moderna, em transformação, reserva para os historiadores". ${ }^{22}$

Ao apresentar o Perfil Profissional, os projetos referem-se ao historiador, e não ao professor de história, buscando justificar a necessária articulação entre pesquisa e ensino, mesmo quando oferecem as modalidades bacharelado e licenciatura. ${ }^{23}$

Quase que de forma consensual, são apresentadas as seguintes características para a atuação do historiador:

- domínio de conhecimentos teóricos e metodológicos ecléticos, amplos e abrangentes mas, também, verticalizados em termos da historiografia, da pesquisa e das técnicas de resgate e preservação do patrimônio, da memória e da cultura;

- qualificado exercício de sala de aula em todos os níveis de ensino oferecidos no país e em suas diversas dimensões de construção e transmissão do conhecimento, produção e difusão de novos materiais pedagógicos e orientações de pesquisa;

- busca constante da educação continuada;

- disponibilidade sociopolítica de contribuir com os processos de construção da cidadania e da transformação da realidade social, seja no ensino e na pesquisa, seja nos trabalhos de assessoria, divulgação, organização, elaboração e execução de projetos específicos em sua área de atuação.

Ao término do item sobre o perfil desejado pelos projetos analisados, o documento conclui que:

é preciso reconhecer que, do ponto de vista pedagógico, o que mais chama atenção nessa possibilidade de chegar a um perfil consensual do historiador, é a perspectiva de uma outra possibilidade, ou seja, a superação pelas instituições de educação superior brasileiras, da dicotomia bacharelado e licenciatura, no curso de História. Essa superação representaria, em termos acadêmicos, a conquista de uma formação integral - ensino e pesquisa, articulada a um vasto e comum campo de atuação com vistas a aprofundamentos teórico-metodológicos específicos e execução prática seja, para bacharelandos seja, para licenciados. ${ }^{24}$ 
Como já afirmado, os projetos que apresentam os objetivos do curso, competências e habilidades do historiador, fazem-no com base nas Diretrizes Curriculares Nacionais de História, reproduzindo, muitas vezes, palavras ou trechos inteiros desse documento. $\mathrm{O}$ teor apresentado pela maioria dos projetos é bastante semelhante, mesmo que recorrendo a diferentes expressões ou formas de redação. E, na verdade, mesmo que provenientes de diferentes regiões do país, coincidem também com os pressupostos indicados no item anterior, sobre o perfil do historiador. O documento do Inep em questão - que apresenta a análise dos projetos pedagógicos dos 199 cursos de História -, a cada item abordado, busca exemplificar ou reforçar, reproduzindo excertos dos projetos de cada região do país. E para reiterar a ideia de que a análise dos projetos possibilitou a percepção da "existência de um movimento, mesmo que não oficialmente organizado, de articulação entre posturas epistemológicas, teórico-metodológicas e pedagógicas em curso, permeando as instituições que oferecem Cursos de Graduação em História”, apresenta um grande trecho do projeto de uma instituição paulista - todo um item, denominado "O ofício do historiador na perspectiva da Política Acadêmica”. Neste item, logo no início, apresenta-se uma questão norteadora: "o que significa educar para a cidadania do ponto de vista de quem lida com a memória?”. Em seguida, são tecidas algumas considerações sobre o conceito memória e respondida a questão inicialmente proposta:

educar para a cidadania na perspectiva de quem lida com a memória significaria exatamente devolver a grupos e indivíduos - por meio da revelação das intricadas construções da memória, que se impõe coletiva, e mesmo da história que se impõe como memória - a possibilidade de recuperarem as suas memórias substrato das suas experiências e lutas, depositárias de direitos que se evidenciaram - significaria devolver-lhes a visibilidade de suas ações enquanto sujeitos da própria história. ${ }^{25}$

O trecho do projeto dessa universidade paulista parece utilizar como argumento e embasamento teórico a discussão realizada durante o Seminário Memória - direito ao passado, organizado pelo Departamento do Patrimônio Histórico (DPH) da Secretaria Municipal de Cultura de São Paulo, durante a gestão de Luíza Erundina, no início da década de 1990. Tal argumentação revela um trânsito entre debates no campo historiográfico assim como uma 
articulação entre concepções e vivências em diferentes instituições, como no caso um departamento de pesquisa que trabalha, entre outras, com a questão do patrimônio histórico em uma universidade.

Outras questões, tais como políticas de patrimônio histórico, preservação do meio ambiente, direitos à pluralidade e à cidadania cultural, são abordadas e apresentadas como fundamentais para a atuação do historiador:

Para além das instituições escolares, que facilmente apareceriam em cena, o historiador ainda educa quando promove suas pesquisas e as publiciza; quando atua em museus e arquivos; quando é chamado à mídia em geral; quando atua junto a movimentos sociais que reivindicam preservação ou junto aos poderes públicos na definição e implementação de políticas que objetivam a cidadania cultural.

Ao final do texto, a possibilidade de articulação entre ensino e pesquisa na formação do historiador é assim explicitada:

É preciso partir do momento histórico atual, ou seja, da divisão pesquisador-professor. Nós a admitimos como uma realidade concreta e, em razão de sua concretude, superável. Mantendo espaços que possibilitem a formação para a pesquisa, para o ensino e - o que é novo - para a experiência cultural, devemos procurar meios pelos quais esses diferentes campos possam dialogar. A chave do processo está na criação de atividades mediadoras entre eles, isto é, na preparação de exercícios de construção do discurso histórico que estejam associados ao trabalho no interior da escola.

Portanto, a divisão alienante não pode ser vista como falsa, afinal existem diferenças concretas - históricas - entre a ação de produzir e a de ensinar ciência. Mas, por outro lado, ela não deve ser admitida como a "dura realidade", insuperável, diante da qual resta apenas a resignação, ou seja, a escolha entre formar o técnico-educador ou o cientista-pesquisador.

É preciso formar para a pesquisa e para o ensino, propondo experiências em que as duas partes da formação dialoguem e, talvez, se superem. Eis o desafio.

Em relação ao elenco de disciplinas que compõem os currículos dos diferentes cursos de História - que apresentam no mínimo 25, e no máximo 60 disciplinas -, a equipe do Inep identificou três grupos: disciplinas teóricas comuns (obrigatórias e complementares) ao bacharelado e à licenciatura; disciplinas teóricas e práticas específicas da licenciatura em História e Estudos 
Sociais; disciplinas teóricas e práticas complementares às três habilitações (bacharelado, licenciatura e estudos sociais).

Além das disciplinas, os projetos pedagógicos indicaram atividades complementares como seminários, semanas de estudos específicos, atividades interdisciplinares e interdepartamentais, programas de bolsas de pesquisa e monitorias, atividades de laboratório, diferentes formas de organização para a realização dos estágios supervisionados e prática de ensino, como também para o processo de elaboração das monografias.

\section{CONSIDERAÇÕES FINAIS}

De maneira geral, os projetos pedagógicos dos cursos de graduação em História revelam a tentativa de se adequar à preocupação de formar o professor pesquisador, de aproximar a formação do bacharelado e a licenciatura. Em alguns casos, a concepção dos projetos vai além de uma mera adequação às normas ou legislação. No entanto, quase sempre, o início da reformulação ocorreu a partir das novas normas federais. ${ }^{26}$

A maneira como os cursos de História absorveram, interpretaram e adaptaram sua estrutura curricular às novas exigências federais revela intenções, peculiaridades, sugerindo a persistência ou tentativas inusitadas para superação da dicotomia entre licenciatura e bacharelado. A ampliação de carga horária para a disciplina Prática de Ensino, segundo a $\mathrm{LDB},{ }^{27}$ tornou explícitas tensões entre professores das faculdades de História e das faculdades de Educação. A formação do professor de História, até esse período, não era um tema pautado pelos departamentos de História, na medida em que essa formação se resumia a frequentar as disciplinas pedagógicas oferecidas na Faculdade de Educação, especialmente em universidades públicas.

No caso de instituições privadas, o impacto da nova legislação é diferenciado, justamente por sofrer diretamente a demanda do mercado de maneira muito mais aguda. Esse diferencial entre as instituições públicas e privadas - a pressão explícita do mercado - é perceptível, até mesmo, em outros momentos de reformulações curriculares dos cursos de graduação em História, como, por exemplo, a exigência da implantação do curso de Estudos Sociais, na década de 1960, ou a tentativa de oferecer um curso integrado de licenciatura e bacharelado, na década de 1980. A implementação de reformulações curriculares 
nas instituições privadas considera, de forma bastante clara, avaliações e análises relacionadas ao mercado de trabalho. Nesse sentido, tais instituições que já apresentavam iniciativas que mantêm seus alunos em contato, ainda que de maneira irregular, com experiências no ensino fundamental e médio, buscaram, também de maneira não uniforme, complementar a licenciatura com elementos de uma formação para a pesquisa, o que, até então, esteve restrito ao bacharelado.

As orientações legais, ao se efetivarem nas universidades, são profundamente permeadas pelas trajetórias pessoais dos professores universitários; pelos embates entre departamentos no interior da mesma universidade; pelas características organizacionais das universidades e pela demanda do mercado de trabalho. No que interessa a este estudo, essa transição entre o escopo da nova legislação, a formulação de um novo currículo e a prática concreta em sala de aula parece colocar a política de formação de professores ainda como uma questão não resolvida no interior das universidades. As soluções encontradas parecem continuar vinculadas ao engajamento pessoal, e não institucional, dos professores universitários envolvidos nesta questão.

\section{REFERÊNCIAS}

ANDRÉ, Marli Eliza Dalmazo Afonso de. Formação de professores no Brasil (19901998). Brasília: Inep/MEC, 2002.

ASSOCIAÇÃO Nacional de Política e Administração da Educação (ANPAE). Audiência Pública Regional CNE. Goiânia, 21 mar. 2001 (mimeo).

ASSOCIAÇÃO Nacional dos Professores Universitários de História (ANPUH). Sobre as Diretrizes Curriculares dos Cursos de História. Fórum Nacional de Coordenadores de Pós-Graduação em História. 27 nov. 1998.

ASSOCIAÇÃO Nacional dos Professores Universitários de História (ANPUH). Sobre o Provão. Diretoria Nacional; Representantes de núcleos regionais; GT/Ensino. São Paulo, 22 nov. 2001.

ASSOCIAÇÃO Nacional pela Formação dos Profissionais da Educação (ANFOPE). Documento do X Encontro Nacional, 2000. (mimeo).

BARBOSA, Ivone Garcia. Análise da versão preliminar da proposta de diretrizes para a formação inicial de professores da educação básica, em curso de nível superior. Goiânia: ANFOPE/FORUMDIR, 2001. 
BRASIL. Ministério da Educação. Lei de Diretrizes e Bases da Educação Nacional, n ${ }^{\circ}$ 9394, de 20 dez. 1996.

BRZEZINSKI, Iria. Contribuições na Audiência Pública Regional Centro-Oeste sobre "Diretrizes para a Formação Inicial de Professores da Educação Básica em curso de Nível Superior”, realizada em Goiânia, 21 mar. 2001 (mimeo).

CANDAU, Vera Maria. A formação de educadores: uma perspectiva multidimensional. Em aberto, Brasília, v.1, n.8, p.19-21, ago. 1982.

CARVALHO, Anna Maria Pessoa de (Coord.) Formação Continuada de professores: uma releitura das áreas de conteúdo. São Paulo: Pioneira Thomson Learning, 2003.

CASTRO, Maria Helena Guimarães de. "Apresentação". Sinopse Estatística da Educação Superior. Censo 2000. Brasília: Sistema de Avaliação do Ensino Superior, Inep/MEC, 2001.

CONSELHO Nacional de Educação (CNE). Proposta de Diretrizes para a formação inicial de professores da educação básica, em cursos de nível superior (versão preliminar). Brasília, fev. 2001.

DIRETRIZES Curriculares dos cursos de História - Aprovadas pelo Parecer CNE/ CES n. 492/2001.

ESTEVES, Manuela; RODRIGUES, Ângela. A análise de necessidades na formação de professores. Porto: Porto Ed., 1993.

EXAME Nacional de Cursos - 2002. Projetos Pedagógicos dos Cursos de História: uma análise. Brasília, set. 2001.

FENELON, Déa Ribeiro. A formação do profissional de História e a realidade do ensino. Projeto História, São Paulo: PUC, 1982.

FENELON, Déa Ribeiro (Coord.) Diagnóstico e Avaliação dos Cursos de História no Brasil: Documento Final. Brasília: MEC/SESu, 1986.

FERRAZ, Leila Nivea Bruzzi. Formação e profissão docente: a postura investigativa e o olhar questionador na atuação dos professores. Movimento - Profissão docente: teoria e prática, Revista da Faculdade de Educação da UFF, Niterói, n.2, set. 2000.

FIGUEIREDO, Antonio MacDowell. Avaliação das condições de oferta dos cursos de graduação. In: Avaliação da Educação Superior: a experiência do Reino Unido e do Brasil em debate. Brasília: Inep/MEC, 2001.

FORGRAD. Contribuição à apreciação da versão preliminar da Proposta de Diretrizes Curriculares para a Formação de Professores da Educação Básica. Brasília: Diretoria do Fórum de Pró-Reitores de Graduação das Universidades Brasileiras, 13 mar. 2001.

GARRIDO, Elsa. Manifestação da ANPEd. 2001. (mimeo). 
GARRIDO, Elsa. Presença e contribuição da ANPEd no debate nacional sobre as diretrizes relativas à Formação do Professor. 2001. (mimeo).

INEP/MEC. Avaliação da Educação Superior: a experiência do Reino Unido e do Brasil em debate. Brasília, 2001.

INEP/MEC. Resultados e Tendências da Educação Superior: Brasil. Brasília, 2000.

INEP/MEC. Sinopse Estatística da Educação Superior: Censo 2000. Sistema de Avaliação do Ensino Superior. Brasília, 2001.

LÜDKE, Menga; GOULART, Sílvia M. Licenciatura: novos caminhos pela via da interdisciplinaridade. REUNIÃO ANUAL DA ANPED, 17., Caxambu, 1994. Anais... Belo Horizonte: Anped, 1994.

MAUÉS, Olgaíses Cabral. Análise da versão preliminar da proposta de diretrizes para a formação inicial de professores da educação básica, em curso de nível superior. Belém: FORUMDIR, 2001.

MEC-SESu/ Depto. de Política do Ensino Superior/ Coordenação das Comissões de Especialistas de Ensino/ Comissão de Especialistas de Ensino de História. Padrões de Qualidade e Critérios de Avaliação dos Cursos de Graduação em História. Brasília, fev. 1997. (mimeo).

MESQUITA, Ilka Miglio de. Formação de professores de História: experiências, olhares e possibilidades (Minas Gerais, anos 80 e 90). Dissertação (Mestrado) - Universidade Federal de Uberlândia. Uberlândia, 2000.

NEVES, Fernando Jorge Rodrigues. Contribuições à apreciação da versão preliminar da Proposta de Diretrizes Curriculares para a Formação de Professores da Educação Básica. Brasília: FORGRAD, 2001.

NOSELLA, Paolo. Compromisso político como horizonte da competência técnica. Educação e Sociedade, São Paulo, v.14, p.91-97, 1983.

NÓVOA, Antônio; POPKEWITZ, Thomas S. (Org.) Reformas educativas e formação de professores. Lisboa: Educa, 1992.

PARECER no 109/2002 - Consulta sobre aplicação da Resolução de carga horária para os cursos de Formação de Professores - MEC.

PARECER no 109/2002 - Consulta sobre aplicação da Resolução de carga horária para os cursos de Formação de Professores - MEC.

PARECER no 1363/2001 - Retificação do Parecer CNE/CES 492/200 - História MEC.

PARECER no 1363/2001 - Retificação do Parecer CNE/CES 492/200 - História MEC.

PARECER n 492/2001 - Diretrizes Curriculares Nacionais dos cursos de História MEC. 
PARECER n 492/2001 - Diretrizes Curriculares Nacionais dos cursos de História MEC.

PARECER nº 583/2001 - Orientação para as diretrizes curriculares dos cursos de graduação - MEC.

PARECER no 583/2001 - Orientação para as diretrizes curriculares dos cursos de graduação - MEC.

PARECER n 583/2001 - Orientação para as diretrizes curriculares dos cursos de graduação - MEC.

PARECER nº 776/97 - Orientação para as diretrizes curriculares dos cursos de graduação - MEC.

PARECER nº 776/97 - Orientação para as diretrizes curriculares dos cursos de graduação - MEC.

PARECER n 776/97 - Orientação para as diretrizes curriculares dos cursos de graduação - MEC.

PORTARIA no 3020, de 21 dez. 2001 - Sobre Exame Nacional de Cursos de História - MEC.

PORTARIA n 3020, de 21 dez. 2001 - Sobre Exame Nacional de Cursos de História - MEC.

PORTO, Rita de Cássia Cavalcanti. Análise da versão preliminar da proposta de diretrizes para a formação inicial de professores da educação básica, em curso de nível superior. Recife: ANFOPE, 2001.

RESOLUÇÃO 13 - Estabelece as Diretrizes Curriculares para os cursos de História MEC.

RICCI, Claudia Sapag. A formação do professor e o ensino de História: espaços e dimensões de práticas educativas (Belo Horizonte, 1980/2003). Tese (Doutorado) FFLCH, USP. São Paulo, 2003.

SILVA, Marcos Antonio da. História: o prazer em ensino e pesquisa. São Paulo: Brasiliense, 1995.

\section{NOTAS}

${ }^{1}$ Cf. Parecer Homologado - Despacho do Ministro, publicado no Diário Oficial da União (DOU) de 25 jun. 2015, Seção 1, p.13; Resolução CNE/CP 2/2015. DOU, Brasília, 2 jul. 2015 - Seção 1 - p.8-12; Retificação publicada no DOU de 3 jul. 2015, Seção 1, p.28.

${ }^{2}$ Cf. Parecer CNE/CES 492 de 3 abr. 2001 (Diretrizes curriculares dos cursos Filosofia, História, Geografia, Serviço Social, Comunicação Social, Ciências Sociais, Letras, Biblioteconomia, Arquivologia e Museologia), homologado em 4 jul. 2001, publicado no DOU em 
9 jul. 2001; Parecer CNE/CES nº 1363, aprovado em 12 dez. 2001 - Retificação do Parecer CNE/CES 492/2001, que trata da aprovação das Diretrizes Curriculares Nacionais dos Cursos de Filosofia, História, Geografia, Serviço Social, Comunicação Social, Ciências Sociais, Letras, Biblioteconomia, Arquivologia e Museologia, Homologado em 25 jan. 2002, publicado no DOU em 29 jan. 2002 e a Resolução CNE/CES n 13, aprovada em 13 mar. 2002 - Estabelece as Diretrizes Curriculares para os cursos de História, publicada no DOU de 9 abr. 2002. Seção 1, p.33.

3 "O Grupo de Consultores foi constituído, inicialmente, pelos professores Francisco José Calazans Falcón/UFF (relator), Déa Ribeiro Fenelon/Unicamp (Coordenadora), Adalgisa Maria Vieira do Rosário/UnB (Secretária), Alice Piffer Canabrava/ Presidente da Anpuh, João Batista Pinheiro Cabral/UnB, Joana Neves/UFPB, Maria José Féres Ribeiro/UFJF e Antônio José Barbosa/SESu-MEC. Posteriormente, a partir da segunda reunião do Grupo de Consultores, foi sugerida a inclusão dos professores Ruth Morais/UFPA e Sandra Jatahy Pesavento/UFRGS, e a professora Alice Canabrava foi substituída pelo professor José Ribeiro Júnior, novo presidente da Anpuh.” Diagnóstico e Avaliação dos Cursos de História no Brasil - Documento Final, p.6.

4 "Foram recebidos, inicialmente, apenas dez documentos (PUC/SP, Unicamp, UFF, PUC/ RJ, UFRGS, UFPE, UFJF, UFBA, UE Ponta Grossa, USP), somando-se a esse total, posteriormente, mais dois (UFRJ e UF Paraíba). Note-se, ainda, que nem todos detiveram-se na análise dos pontos sugeridos pelo GC, limitando-se ao problema estritamente curricular. Apesar da baixa representatividade, julgou o GC que valeria a pena discutir e tentar resumir as questões levantadas pois, apesar de tudo, é evidente que as respostas recebidas partiram de algumas das principais universidades do país, restando apenas a lamentar a omissão de tantos Departamentos igualmente interessados nos problemas da graduação em História.” Diagnóstico e Avaliação dos Cursos de História no Brasil - Documento Final, p.12-13.

${ }^{5}$ Ibidem, p.13-14.

${ }^{6}$ EXAME Nacional de Cursos 2002.

${ }^{7}$ Essa associação - pesquisa e trabalhos escolares - surgiu, muitas vezes, quando da aplicação dos questionários a alunos de início e término do curso de História de Belo Horizonte, na pesquisa da qual resultou a tese de doutoramento $A$ formação do professor e o ensino de história: espaços e dimensões de práticas educativas (Belo Horizonte, 1980/2003). Em todas as instituições e períodos pesquisados, alunos solicitaram esclarecimentos sobre a questão "Você já realiza ou realizou algum trabalho na área de pesquisa?". O questionamento feito era se trabalhos das disciplinas do curso e pesquisas na biblioteca poderiam ser considerados como trabalho na área de pesquisa.

${ }^{8}$ Diagnóstico e Avaliação dos Cursos de História no Brasil - Documento Final, p.17.

9 Trata-se da professora Lívia de Oliveira.

${ }^{10}$ 1) O profissional de História e o Mercado de Trabalho; 2) Articulação da Universidade com o Ensino de $1^{\circ}$ e $2^{\circ}$ graus; 3 ) A Questão do Currículo Mínimo e Pleno. 
${ }^{11}$ A Comissão de Especialistas de Ensino de História, em fevereiro de 1997, era composta por Claudia Sapag Ricci (UFMG), Laura Antunes Maciel (PUC/SP), Olga Brites (PUC/SP) e Marcos Silva (USP/SP).

${ }^{12}$ MEC-SESu/ Depto. de Política do Ensino Superior/ Coordenação das Comissões de Especialistas de Ensino/ Comissão de Especialistas de Ensino de História. Padrões de Qualidade e Critérios de Avaliação dos Cursos de Graduação em História. Brasília: MEC-SESu, fev. 1997 (mimeo, p.17).

${ }^{13}$ Esse texto é apresentado no site do Ministério da Educação: www.mec.gov.br/Sesu/diretriz.shtm.

${ }^{14}$ Segundo o Art. 53 inciso II da LDB, a universidade tem autonomia para "fixar os currículos de seus cursos e programas, observadas as diretrizes gerais pertinentes". O movimento que se instaura é, de certa forma, uma tentativa de regulamentação desse artigo, na medida em que o MEC busca a elaboração de diretrizes curriculares para os cursos de graduação.

${ }^{15}$ O Fórum de Pró-Reitores de Graduação das Universidades Brasileiras (ForGrad), criado em Ouro Preto, em 1988, tem sido uma instância que possibilita a articulação das discussões para implementação de mudanças no sistema universitário.

${ }^{16}$ Esse documento é assinado pela Comissão de Especialistas do MEC - Ciro Flamarion Cardoso; Elizabeth Cancelli; Luzia Margareth Rago; Associação Nacional de História Anpuh - e traz a seguinte observação: "texto modificado pelo Fórum Nacional de Coordenadores de Pós-Graduação em História, em 27 de novembro de 1988”.

${ }^{17} \mathrm{O}$ grifo revela as alterações no texto BRASIL-MEC/ Secretaria de Educação Superior/ Departamento de Políticas do Ensino Superior - Diretrizes Curriculares dos Cursos de História, 1999, citado em MESQUITA, 2000, p.42.

${ }^{18}$ EXAME Nacional de Cursos 2002.

${ }^{19}$ São inúmeros os documentos e fóruns que tiveram como objeto de debates a questão das Diretrizes Curriculares dos Cursos de Licenciatura.

${ }^{20}$ Documento fruto da reunião da Diretoria Nacional da Anpuh com representantes de núcleos regionais e o GT/Ensino da entidade, realizada em São Paulo no dia 22 de novembro de 2001.

${ }^{21}$ Ver: EXAME Nacional de Cursos 2002, p.3.

${ }^{22}$ EXAME Nacional de Cursos 2002, p.4.

${ }^{23}$ Essa perspectiva aparece até mesmo nos projetos pedagógicos dos Cursos de Estudos Sociais, como por exemplo o apresentado pela Universidade do Oeste Paulista: "o profissional estará assim capacitado a exercer o magistério nos Ensinos Fundamental e Médio, apto a associar ensino e pesquisa, a resgatar e preservar o patrimônio, a memória, a cultura e a assessorar as entidades públicas e privadas nos setores culturais, artísticos, turísticos e outros" (grifos meus). 
${ }^{24}$ EXAME Nacional de Cursos 2002, p.12.

${ }^{25}$ Projeto Pedagógico da Universidade Metodista de Piracicaba - SP citado em EXAME Nacional de Cursos 2002, p.16-17.

${ }^{26}$ O Edital no 04 - SESU-MEC, datado de 10 de dezembro de 1997, convoca as Instituições de Ensino Superior a apresentar propostas para as novas Diretrizes Curriculares dos Cursos Superiores.

${ }^{27}$ Art. 65 LDB n 9394/96 - A formação docente, exceto para a educação superior, incluirá prática de ensino de, no mínimo, trezentas horas.

Artigo recebido em 14 de junho de 2015. Aprovado em 14 de julho de 2015. 